\title{
Responsibilities of Manager and Leader in Relation to the Reduction
}

\author{
of Workplace Stress*
}

\author{
Li Qian \\ School of Humanities and Law \\ Northeastern University \\ Shenyang, China \\ liqian3102@126.com
}

\author{
Li Qian \\ School of Management, \\ Jilin Normal University \\ Siping, China \\ liqian3102@126.com
}

\begin{abstract}
Pressure is part and parcel of all work and helps to keep us motivated. But excessive pressure can lead to workplace stress which undermines performance, is costly to employers and can make people ill. To reduce the stress the leaders and managers should undertake different responsibilities in their own station. The current essay analyzed the major sources of workplace stress firstly. Then the responsibilities of a manager and a leader were analyzed respectively. Differences between leaders and managers responsibility to alleviate workplace stress is the focus of this essay, and make this article differs from other related studies.
\end{abstract}

Keywords: workplace stress; manager responsibilities; leader responsibilities; stress reduction

\section{INTRODUCTION}

Stress has been defined as the relationship between a person and his/her environment that is perceived to be unbalanced in terms of one's physical and psychological resources and the demands of the situation (Lazarus and Folkman 1984)2. Workplace stress is often related to the design of the job, the culture and environment of the workplace setting, relationships that exist in the workplace, or some combination of these (Yoo et al. 2009)3. The Health and Safety Executive (HSE) define stress as "the adverse reaction people have to excessive pressures or other types of demand placed on them". Recent research shows that this 'adverse reaction' can seriously undermine the quality of people's working lives and, in turn, the effectiveness of the workplace. There is a growing awareness of

* Fund Project: Study on The Theory and Method to Improve the Performance of College Teachers (No. 13YJA880064, Research Project in Humanities and Social Sciences by the Ministry of Education of China), from 2013 to 2015. the importance of health and safety and recognition that healthy employees make a greater contribution to a business. People are more aware of the harmful effects of stress in workplaces but it is not new psychologists have been studying stress since the 1950s.

Most of the existing research pay attention to workplace stress faced by managers and leaders, this essay will focus on how managers and leaders to exercise their responsibility to reduce workplace stress faced by other members of the organization. The remainder of the essay is organized in the following way. In section 2 we analyzed manager's responsibility to reduction of workplace stress, and analyzed leader's responsibility to reduction of workplace stress in section 3. Concluding remarks follow.

\section{MANAGER'S RESPONSIBILITY}

As Peter Drucker says, "Management is doing things right; leadership is doing the right things."8 The reduction of workplace stress means to bring about a reduction in the number of employees who go off sick, or who cannot perform well at work because of stress. Managers are usually the person in designated positions. Managers have a job position or title that lets others know they are in charge. They are the people who make things happen and get things done. They take the leader's vision and organize whatever needs to be done to make the vision a reality. The ability to manage well is more a 'left-brain activity', involving structure and organization. There are many qualities and skills managers must possess in order to do 
their job well. In order to achieve this aim, the responsibilities of a manager in relation to the reduction of workplace stress as following:

\section{A. Plan and Perform}

Excellent plans to make all members of the work to determine the formation of expectations and effectively reduce workplace stress with the uncertainty about the future. Good managers understand and create systems and know which ones will work best to enable their team to be most effective and efficient. Managers should have the ability to multitask and keep track of a lot of things at once. Effective managers keep detailed daily notes about all that happens on the unit. With the help of these notes they are able to make decisions, delegate, create schedules, and monitor work climate. A good manager is in touch with all that is happening in the unit on a 24-hour basis.

\section{B. Engage in Dialogue and Debate, not Coercion}

To maintain the enthusiasm of members, manager should give credit at every opportunity for successes and a job that is well done, and pass on compliments. At the same time, excellent manager will accept responsibility for things that go wrong. Ultimately it's your responsibility to insure that you have the right staff members in the right positions, and that they are well trained. If something goes wrong it's because this hasn't happened. Let people know how they are doing, and offer praise often. Verbally appreciate people in private and in front of others. If correction is needed, give it privately and with respect, and focus on the positive and your belief in their ability to improve.

\section{Delegate Tasks Rationally}

Fair distribution of tasks can effectively alleviate workplace stress. Effective managers direct staff to complete tasks in the most time and financially efficient ways possible. This requires knowledge of each individual team member's abilities, preferences, and learning needs. They give clear, complete instructions designed to communicate to each employee based on their experience and ability. A good manager is able to speak the language of their team members and to meet them at their level. Good managers will be flexible and able to move quickly from one role to another. They wear many hats, and may be required to switch from counseling to educating to delegating within a short period of time.

\section{Solve Problems Without Blame}

Employees in the task implementation will inevitably encounter various difficulties and resulting workplace stress. Good managers face situations realistically and deal with them immediately. They deal with issues, not emotion, and focus on what was learned from a situation and how it can be done differently next time. This helps to move their staff members forward rather than keeping them stuck in mistakes. When Listen, ask questions and respect answers. Good managers are effective communicators. They are approachable and believe that each person has a right to an opinion, something to offer the team, and has a right to be heard.

\section{E. Matching Tasks and Employees Reasonably}

There are still differences in ability between different members although within the same organization, which resulted in problems of matching skills and jobs. When a manager assigns a task to a team member s/he demonstrates faith and respect in the ability of that member to do the job to the best of their ability. Managers are aware of the specific personalities and learning needs of each of their employees. An effective manager meets with each team member to discuss job satisfaction and goals for personal and professional growth. Together the manager and employee create action plans to move the team member toward the goals.

\section{LEADER'S RESPONSIBILITY}

Managers and employees will ignore a large proportion of workplace stress when they believe the organization get forward in the right direction. The leader's responsibility is to lead the organization in the right direction. To maintain the entire organization efficiently operation leaders are 
obliged to keep the whole organization managers and employees have a comfortable working environment. For reduce workplace stress, leaders need to exercise their various duties effectively. The responsibilities of a leader in relation to the reduction of workplace stress as following:

\section{A. Activate Work Environment}

One potentially powerful way for leaders to cultivate an active work environment is to foster self-leadership in them and in their employees. Self-leadership is the most effective method to relieve stress in an organization with exceeded workplace stress. The ability to lead is not connected to education, although most leaders are intelligent people. Leading is a "right-brain activity", more about creating and following vision than about structure and organization. To an effective leader is a person others will respect and follow. Leadership is about influencing those you lead, and there are several qualities and characteristics a leader must possess to do this. Have a clear vision of where the group is going.

\section{B. Accurate Understanding of the Current}

\section{Situation}

Leaders may not know some specific operations, but must keep a deep understanding of the current situation at all times. To reduce the stress, leaders should be clear on the reality of whatever situation they are currently in, and also believe completely that they will eventually prevail. This mindset is exemplified by the attitude of Admiral James Stockdale, who was the highest-ranking US military officer imprisoned in Viet Nam. He was a prisoner in the most horrible conditions for over eight years, and his description of those who survived and those who didn't illustrates this quality. He says that those who survived were not the optimists, who said "We'll be home by Christmas, or we'll be home by next Easter". For when those dates came and went, these men became more and more disheartened, and eventually died of a broken heart. Those who survived were the ones who "never lost faith in the end of the story.

\section{Reasonable Arrangements and Fully Authorized}

Authorization systems provide modern distributed applications programmers a more effective and scalable means of specifying and enforcing authorization policies (Peter C. et al. 2008)11. Authorization is the basis for the completion of the target responsibility. The exercise of power for manager is responsible to the assignment. Corresponding responsibilities with power to ensure manager achieve their goals effectively.

Full authorization can reduce workplace stress to the greatest extent, however, authorization only still not sufficient. Leaders also need democracy. Listen well and lead with questions, not answers can fully display the authorization and trust. Leaders are much more interested in listening and learning than telling and directing. Respect people at all levels and always want to hear what they have to say. Good leaders realize that everyone in their organization is equally valuable and important to the overall success of the business. All jobs are built on each other, and what the janitor does is just as important as what the CEO does.

\section{Have Strong Values and Beliefs}

As an effect leader to reduce workplace stress s/he should have strong values and beliefs, and live them in every area of their life. It's important to be congruent in all. Possess positive self-esteem and are self-confident without being arrogant. Self-esteem is how you feel about yourself and the person you are. People with positive self-esteem maintain high output even though they are in the face of workplaces with high stress. Self-confidence is how you feel about your ability to function in a given situation, and comes from responses or feedback from others.

Leader should have the courage and strength to make difficult decisions. Decision-making requires that you evaluate the entire situation and move in the direction where the outcome will 
benefit the most people and your organization. This involves evaluating the pros and cons of possible outcomes, and being willing to take a stand that may be unpopular if you feel it's the best way to go. Good leaders are also diplomatic about the way they do this, so people don't feel stepped on.

\section{E. Passionate about Everything}

Leaders' enthusiasm will affect every member of the organization. It's clearly that organization which each member is full of enthusiasm for the work has a better ability to resist workplace stress. If correction is needed, they give it privately and with respect, and focus on the positive and their belief in their team member's ability to improve. The other side of passion is to give credit to others for successes, and accept personal responsibility for failures. Good leaders believe that if there is a failure, it's his/her responsibility, if things are fine it's our doing, and if there is a success it's because of the team or an individual member.

\section{CONCLUSIONS}

Workplace stress is a major cause of occupational ill health, poor productivity and human error. It is also widely recognized that managers and leaders experience of stress is a complex issues, which influenced by a large number of factors which may be work-related, personal, external or indeed due to a combination of these. It is therefore unrealistic to expect that we will manage to eliminate workplace stress entirely. However, there is much we can do as managers and leader to reduce its likelihood and support those unfortunate enough to experience it.

\section{REFERENCES}

[1] HSE (Health and Safety Executive) tackling stress, Stress-related and psychological disorders in Great Britain (GB). 2013

[2] Lazarus, R., \& Folkman, S. Stress, appraisal, and coping.New York, NY: Springer. 1984.

[3] Yoo, H. L., Eisenmann, J. C., \& Franke, W. D. Independent and combined influence of physical activity and perceived stress on the metabolic syndrome in male law enforcement officers. Journal of Occupational and Environmental Medicine, 2009.51:46-53.

[4] Paton N. Tackling workplace MSDs. Occup Health Magazine (EXTRA) 2005;57(9):7-9.

[5] Koushiki Choudhury.Managing Workplace Stress:The Cognitive Behavioural Way. Springer India Heidelberg New York Dordrecht London, 2013.

[6] Eleni Moustaka, Theodoros C Constantinidis. Sources and effects of Work-related stress in nursing. HEALTH SCIENCE JOURNAL. 2010.4(4):210-216.

[7] Peter F. Drucker, Essential Drucker: Management, the Individual and Society. Routledge. 2001.6.

[8] Peter C. Chapin, Christian Skalka, X. Sean Wang, Authorization in Trust Management: Features and Foundations, ACM Comput. Surv., 2008,40(3):1-48. 